\title{
The market, the regulator, and the government: Making a blockchain ecosystem in the Netherlands
}

\section{Inês Faria}

University of Lisbon, Portugal

\begin{abstract}
This article presents a socio-anthropological analysis of the formation of a business ecosystem around blockchain technology in the Netherlands, within the broader context of the European Union and the digital single market. I argue that while reproducing widespread global models of business group and network formation, the relations created by these networks also reveal particularities of local business and governance cultures. Such particularities emerge from the pragmatics of collaboration and competitive market relationships, as well as legal heterogeneity and plans for legal harmonisation in digital innovation and governance in Europe. They also emerge from the challenges and transformations that current experimentation cultures for digital innovation bring to the interactions between market players, regulators, and government. These challenges and transformations materialise in increasingly informal connections and strategies for experimental legitimisation, which occur in parallel to more formal and traditional forms of regulatory and governmental interaction. The article is based on ethnographic fieldwork in the Netherlands and in online terrains, including observation periods and 32 interviews with entrepreneurial project teams, as well as with individuals involved in financial incumbents' innovation labs.
\end{abstract}

\section{Keywords}

Blockchain, digital identification, business networks, regulation, European Union, Netherlands

\section{Introduction}

The concept of ecosystem was transported into innovation and business management decades ago to describe the idea of firms and other stakeholders working and co-evolving together, in a delicate balance between collaboration and competition, to establish an 
environment in which they can thrive (Moore, 1993). Beyond having a certain degree of informality, ecosystem dynamics are rather decentralised and flexible (Powell, 1990; Kogut et al., 1995; Walker et al., 1997; Kogut, 2012), with actors striving to define and attain both common interests (Todeva, 2006) and a common ground where competition is possible.

Finance is a good example of these dynamics, and in the post-crisis market and regulatory configuration - what has been called the fintech era (Zetzsche et al., 2017; Arner et al., 2017; Tsang, 2019) - transformations and challenges to new and incumbent financial actors, as well as regulatory and supervisory authorities, are appearing. It is in this context that experimental business ecosystems and governance models are forming around different technologies and digital innovation.

This article empirically examines the development of digital identification applications and the emergence of the blockchain ecosystem in the Netherlands. As I will show, for the case at stake, these relationships include increasingly informal networks and negotiated collaborations between government, regulators and market players. By informal networks, I mean flexible trustable connections, without formal commitment, that take place in mundane situations (cafés, lunches, events or innovation labs) as well as digitally (through calls, chat applications, social networking and other digital means of communication). Although these connections are not new (Stone, 2011; Weiss, 2020), and they develop in parallel to traditional regulatory approaches and formal interactional models such as public consultations, what I emphasise below regarding identification and the formation of a blockchain ecosystem is that informal social networks in market-making are now more dynamic - they are made of interactions that become faster and shorter, that open up for more continuous conversations and more actors, and which become more flexible and expanded through hybrid (actual/ digital) socio-technical assemblages, motivated by (temporary) global and market common interests (see also Stone, 2011).

A buzzword in fintech circles, blockchain is a system that first appeared with the digital currency Bitcoin. It can be described as a distributed, encrypted, synchronised database (a distributed ledger) that enables the circulation of tokens - cryptocurrencies or others, representing bits of information - which can be used to facilitate both digital transfers and the large-scale coordination of people and/or artefacts (for more see Nakamoto, 2008; Maurer et al., 2013; DuPont and Maurer, 2015; Davidson et al., 2016; Swartz, 2017, 2018). There have been multiple attempts to create ecosystems around blockchain technology, and they involve a delicate balance between collaborative efforts for making markets and the creation of a common digital infrastructure upon which applications can be built in a competitive environment. This particular digital infrastructure - the blockchain protocol - enables decentralised governance architectures (Hayes, 2019; Caliskan, 2020), governed algorithmically through an automated framework.

The practices and socio-technical assemblages (Callon, 1990; Latour, 2005) analysed throughout the article - comprising people and machines, and linking local and global domains - involve regulatory conversations and plans for the formation and expansion of platform economies for the blockchain ecosystem and digital identification (Black, 2002; Langley and Leyshon, 2017). Langley and Leyshon (2017) propose a particular take on the idea of platform capitalism today, dominated by increasingly digitised and decentralised platform and rent-seeking businesses that nevertheless reflect the prevalence, and power, of actual technological, political and economic geographies and jurisdictions. As shown below for the Dutch case, emerging technological ecosystems reveal this globalised framework, and how it encompasses continuities and transformations in the relationships between market, regulator and government, while reflecting particular local traits. 
Overall, the findings in this article contribute to the scarce empirical accounts of market, regulatory and governmental agency (Carruthers and Stinchcombe, 1999; Riles, 2014; Thiemann and Lepoutre, 2017; Lopes, 2018; Fernandez and Wigger, 2017; Engelen, 2015), an area seldom approached through a socio-anthropological lens, particularly when it concerns finance and regulation. The findings also contribute to discussions around experimentation, governance models and regulatory conversations (Black, 2002; Eckert and Börzel, 2012), in particular by revealing a trend towards the increasing informalisation and decentralisation of networked processes of decision-making in emerging international market, regulatory and policy-making arenas (Morgan and Yeung, 2001; Mayer, 2011), thus promoting a growing entanglement between market and politics (Stone, 2011; Thiemann and Lepoutre, 2017). Going beyond previous studies about business network formation and market-making (Carruthers and Stinchcombe, 1999; Engelen et al., 2010; Kogut, 2012), this article offers insights into how these processes are not only expanded by decentralised and automated digital architectures, but also by international regulatory frameworks in the EU and jurisdictional competition within them.

Perhaps in an effort to keep up with the fast pace of technological innovation in multiple attractive markets, current business models are increasingly based on situational networks and transcend the aspects of informality that have been accounted for so far (Black, 2002; Stone, 2011; Thiemann and Lepoutre, 2017). If previous research on informality and the relations between regulator and regulated has focused mostly on financial incumbents, in the current tech ecosystems, small startup players have come to play an important role in marketmaking, becoming yet another facet in what has been called regulatory cognitive capture (Thiemann and Lepoutre, 2017) and informality in politics and economy (Stone, 2011).

As I argue in the following sections, the emergence of digital means of transaction and communication, such as the internet and blockchain technology, as well as of startup culture and more decentralised, informal, connected and fluid modes of organisation, reveals particular liaisons between local business cultures and contemporary global markets for digital financial and governance technologies. These demand that we adopt new modes of looking at, and thinking about, business network and business ecosystem formation, not only from the point of view of market actors, but also emphasising the current role of government and financial regulation and its corresponding supervision practices.

The following section provides details on the study's methodology, followed by a market and regulatory contextualisation for the EU focused on the crucial dimensions of making a globally competitive digital market based on digital identification and the regulatory frameworks that create business opportunities in this expanding area. The empirical section deals with the relations between the market and the regulator, and the market and the state. I then discuss these aspects in light of current debates around platform capitalism, business ecosystem formation and (regulatory) market-making.

\section{Methods}

The research underlying this article is based on multi-sited ethnographic fieldwork (Marcus, 1995) conducted between October 2016 and April 2017 in actual and online terrains. I followed blockchain pilots and proofs of concept, immersed myself in the blockchain community, and cultivated contacts within the financial blockchain ecosystem in the Netherlands. The choice of the Netherlands as a field site within the EU stems from both practical and research-related considerations: the country has a lively digital innovation landscape, and at the time of fieldwork, many initiatives were focusing on blockchain 
technology use-cases. In addition, the country has a particular status within the EU as a business haven that promotes a friendly environment for tech businesses and startup culture, while being manageable in size for an individual research endeavour. The empirical research included the observation of events and moments of work - live and in online conversation channels, which were registered in fieldwork diaries. For a total of six months - two-and-a-half in the Netherlands and the remainder online - a total of 32 semi-structured interviews were conducted. Interviewees included financial actors as well as members of project teams using blockchain technology as an alternative to centralised forms of governance.

These interviews were carried out with people working for regulatory agencies, the banking sector, audit and insurance companies and associations, notary associations, large tech corporations, and members of the teams of three startups using blockchain technology. Additionally, interviews were carried out with members and curators of coalitions striving to develop blockchain technology use-cases at a national level - i.e., groups looking to establish a more unified landscape for experimentation with the technology in the Netherlands, involving government agencies, market players, scientific and academic institutions, and regulatory entities. These conversations took place in Amsterdam, the Hague and Groningen. Additionally, one interview was carried out in Brussels with a blockchain expert at the digital innovation department of the European Banking Federation. The interviews, coordinated with moments of ethnographic observation, allowed for a multi-faceted understanding of discursive resources and narratives related to blockchain technology, as well as the pragmatic practices of the actors involved in the ecosystem in the Netherlands and wider EU and global landscapes.

All interviews were recorded with permission and were transcribed verbatim; when possible during the fieldwork process, the remainder afterwards. For the purpose of this article, some but not all of the collected data and interviews have been used. The names of the respondents in this article have been omitted, though some of the respondents may recognise their own cases. The names of institutions are revealed when pertinent, in order to contextualise statements and the production of certain discourses.

Before focusing on the Dutch context regarding emerging markets for digital identification and blockchain experimentation, I introduce the political and regulatory conjunctures that have created an opening for the development of digital identification markets.

\section{The digital single market and the market for digital identification}

The post-2008 crisis context brought about harmonised EU-wide changes in banking and financial regulation. Current regulatory priorities mainly concern five issues: financial stability, prudential safety and soundness, consumer protection, market integrity, and market development and innovation (Arner et al., 2017; Zetezsche et al., 2017). The current process of fragmentation among financial actors - with fintech startups entering the picture and the rapid development of financial technologies, allied with demands for national or EU-wide competitiveness in international markets - brings new regulatory challenges. Moreover, these challenges appear in a context seemingly distanced from the laissez-faire regulatory posture towards financial innovations of the early 2000s (Arner et al., 2017), which demands more negotiated approaches to emerging markets. In this conjuncture, despite industry lobbying against the premature regulation of new technologies, both industry and regulators are negotiating through less formal channels, in more continuous interactions that keep an environment of increased collaboration in motion, thus going beyond the more traditional reporting, or audit, approaches to financial supervision. This informality, which has been 
accounted for in previous research (Stone, 2011; Thiemann and Lepoutre, 2017), includes, however, more structured forms of supervised experimentation (Zeitzsche et al., 2017; Tsang, 2019) that takes place in a sort of institutionalised informal environment called a regulatory sandbox, which prioritises what Black (2002) has called regulatory conversations.

Since the crisis of 2008 , regulatory intimacy with finance seems to have increased in some areas, manifesting through a continuous dialogue regarding market stability, consumer protection, transparency, digital innovation, and emerging technologies, alongside efforts for EU-wide regulatory harmonisation and banking and financial reform. These seem, nonetheless, insufficient efforts in order to transform financialised business models based on maximising shareholder value and create a common EU-wide consistent financial regulatory framework (Ertürk, 2015). In such a context, government and regulatory attitudes towards cryptocurrencies and blockchain are not harmonised. Despite the EU's normative statements about the perils of cryptocurrencies/virtual currencies (for the latest one, see ECB, 2018), there is a lack of harmonisation on the issue between member states. No definitive opinion and no definite recommended code of conduct have been formed. This leads to some legal heterogeneity, related to national regulatory attitudes towards blockchain technology, cryptocurrencies, crypto activities (such as initial coin offerings [ICOs]) and digital innovation at large. ${ }^{1}$ The Netherlands has an innovation-friendly approach under a liberal, yet cautious, relationship between regulatory, supervisory and governmental entities and market players. Independent of official positionings, in Europe there is a growing openness in jurisdictions towards interaction between the regulator and market players (especially startups) working with blockchain or other developing digital technologies. This often responds to the desire to remain competitive and functional within increasingly digitalised environments.

In a context where the need to innovate and embrace digitisation cohabits with the need for financial regulatory soundness, the EU is striving for regulatory harmonisation, member state connectivity and enhanced competitiveness in the digitisation scene through various measures. These include the digital single market (DSM) strategy, and further quests for regulatory overview through the single supervisory mechanism (SSM). These efforts play an active role in the emergence of new markets. Since the inception of the EU's DSM strategy, and following global government digitisation trends, digital identities and identifications have become a priority topic for member states and financial actors alike (EU, 2015, 2016a; EBF, 2016). Launched in 2015, the consolidation of the DSM proposes the implementation of a Euro-centred market and governance network with the objective of embracing the EU's increasing digital competitiveness in global markets. In this particular regulatory context, interoperable e-identification has become a priority and is covered by e-IDAS regulations (eIDAS, 2014). Today, the main drivers of the discussion around this topic regard the need to have trustworthy, transparent and secure digital identification systems that are interoperable across member states as a first step towards e-government. Digital infrastructure - for digital identification and other bureaucratic matters - has thus become highly attractive as a business opportunity.

Although transparent and immutable, the blockchain protocol is pseudonymous; that is to say, people are not identified unless the protocol, or an application on top of it, is programmed to do so. These characteristics, that align with the subversive cypherpunk character of Bitcoin, are viewed ambiguously by financial regulators and mainstream financial actors. On the one hand, they clash with existing regulations regarding know-your-customer and anti-money laundering; on the other hand, there are characteristics of the system - transparency, immutability, decentralisation and encryption - that make it ideal (in theory) to streamline organisational dynamics and bureaucratic processes, including digital identification. 
The imaginary of Bitcoin - that it can enable the sidestepping of government and traditional market intermediaries in value transfers and payments - is today being appropriated by both the very entities that Bitcoin's creation aimed to make obsolete, as well as a myriad of projects with more libertarian or mutualist narratives (Faria, 2019; Faustino, 2019). With all its characteristics, blockchain, also referred to as distributed ledger technology (DLT) in more conventional business circles and in regulatory terminology, has become a popular technology, and experiments to implement it in order to streamline bureaucratic operations have multiplied in the last couple of years. In addition to its main characteristics its immutability and distributed nature - the possibility of writing self-executing contracts, socalled smart contracts, and the potential of cutting operational costs and increasing efficiency in several areas of business operation draw a lot of attention to and encourage experimentation with the technology (in the areas of banking, logistics, identification, etc.).

There is a tendency to attribute a particular degree of trust to this protocol, due to its immutability and decentralised algorithmic governance: an embedded algorithmic automated regulation feature that feeds a narrative of freedom from human bias in governance and transactions. This, to some extent, attracts both market players and regulatory and governmental entities (I explore this subject elsewhere; see Faria, 2019). Full decentralisation is not fully advocated by mainstream financial actors, and blockchain is a point of interest as long as it is possible to make it permissioned, and to make some nodes more powerful than others; i.e., to make versions of the protocol controlled by a limited number of governing nodes instead of fully decentralised.

Taking this into account, and as a protocol that could streamline large-scale coordination, cutting costs and enhancing security in information storage and transfer, blockchain, or DLT, is therefore being considered as a possible option for digital identification management processes in the long-run. However, given the current state of affairs across EU member states, and for the Netherlands specifically, a definitive solution for identification using this technology has yet to be found. In the Netherlands and elsewhere, many actors are experimentally combining blockchain identification possibilities with upcoming EU regulatory demands regarding digital identification services (Accenture, 2013; NVB and PwC, 2017). These include both private and public actors, such as regulators and government.

\section{The market: Banks and identification as a new business}

When I arrived in the Netherlands for my fieldwork in early February 2017, digital identification was a 'hot topic' in digital innovation agendas, including those of financial actors. Indeed, as a market, digital identity verification is considered to be worth 16 to 22 million dollars (Kochenov and Gstren, 2019: 2). This was a reason for identification being high on the agenda, combined with EU demands for pan-European digital interoperability defined by the eIDAS regulation

In the Netherlands, there is a specific conjuncture for digital identification provision based on a free market for management and verification systems. The Dutch government, in collaboration with private partners, had an already-established set of standards - idensys for federated identity authentication for logins on digital platforms. Alongside this framework, there is DigID, the government e-identification system, and the eHerkenning, the same service for companies. This national liberal market context, together with EU-wide e-IDAS standards, creates a business space that private actors seek to occupy, given that the need for digital identification is, or will be, very widespread. Banks are among such actors and, in 2017, 
during my fieldwork, a platform was about to be launched - iDIN. This software, based roughly on the same principle as iDEAL, aims to create a federated digital identity authentication interface. $^{2}$

A member of the Dutch Banking Association (NVB) whom I met at its headquarters in Amsterdam explained how people could use this software to authenticate digital identification using their bank account login instead of DigID, the bottom line being that banks would, then, be everywhere. In this case, banks would expand their intermediation penetration and rentseeking terrains into increasingly ubiquitous digital interactions, with the plus of likely selling services to the government. In what concerns organisation, iDIN falls under the umbrella of the Dutch Payments Association (DPA) and the Dutch Tax and Customs Administration, in a context where the entanglement between payment systems, governance and digital identification is increasingly dense. In the Netherlands, the coexistence of multiple online identity authentication platforms creates a market where the citizen or organisation may have the option to use the one most convenient for personal and government matters. ${ }^{3}$

In this arena, banks and some financial institutions are in an advantageous position as potential digital identification providers or managers, in the sense that, as trusted third parties in public key infrastructure (PKI) for identity authentication, they can authenticate online identity claims between parties - a service that is increasingly in demand. ${ }^{4}$ This is due both to the current international regulatory context that requires banks to "know their customers' and prevent money laundering (KYC/AML) and terrorist financing, as well as to the sector's social and economic embeddedness.

Banks and other financial actors involved in the experimental implementation of identification systems, through collaborative branched innovation labs, are struggling with the demand for balance between privacy, transparency and security in software development. This is an area where blockchain protocols are considered a potentially viable infrastructure - the system ensures high privacy and security standards at an infrastructural level - provided that a way can be found to make nodes identifiable while granting a degree of privacy and network security.

Blockchain thus enters into various projects of banks and other financial institutions, which, organised in innovation labs, form part of wider digital innovation agendas where experiments in different areas and using diverse technologies are taking place. Besides the digital identity authentication platforms that are already online, such as iDIN, several banks are teaming up to conduct blockchain-based experiments for this purpose. The idea behind these projects is to take advantage of blockchain technology encryption and decentralised storage and security, and combine it with current digital identification applications (e.g., iDIN) and verification systems. Despite all of the ongoing efforts, the main business rationale behind blockchain experiments with digital identities is still to evaluate the viability of replacing current digital ID infrastructure with blockchain infrastructure, and of adapting existing software for verification and authentication, in the hope of opening up potential spaces for business and cost-cutting. Despite high ambitions, these rationales and experiments are being only cautiously developed since, as I shall explore later, while they do have investment and networking potential, materialised in innovation labs, banks do not have the same agility as startups in experimental endeavours.

Dutch banks seem to be responding to markets made by policies and regulations, but they are also tracing a way towards the increase of rent-based revenues by establishing a widespread presence in the digital economic and governance landscape (O'Dwyer, 2015; Langley and Leyshon, 2017). As mentioned elsewhere (Engelen et al., 2010; Engelen, 2015), the multilevel and multi-tech connectivities involved in innovation labs are a way of adapting 
to, but also profiting from, the uncertainties of technological developments (e.g., which technology will be adopted faster? What is the best option?), within the - only partly harmonised - heterogeneous regulatory context of the EU concerning financial activity and emerging digital technologies.

\section{The regulator: Regulatory embeddedness and experiment legitimisation}

In the Netherlands in 2017, regulators had been involved in most blockchain experiments from the onset of the discussion about the technology, its risks and possibilities. My interviewee at the Dutch Central Bank (DNB) told me that regulatory attention to, and involvement in, blockchain experiments had started in 2015, the moment when most large financial institutions had turned their eyes towards the technology. Collaborative efforts were not so enthusiastic in the early days, with the incumbents striving to be included in the regulatory initiatives for digital innovation focusing mainly in fintech startups. At this point, the DNB's participation in use-cases and pilots came from a supervisory angle, oriented more towards supporting new startup projects than the inclusion of financial incumbents in ongoing legal guidance efforts to support technological experimentation. As I observed during fieldwork, the DNB's position would rapidly change towards a more inclusive approach - the fruit of market lobbying but also of exponential growth in the experimentation market - justified by reasons of systemic financial stability and by a desire to take advantage of digital technologies, including blockchain, for regulatory and supervisory purposes (Regtech).

Within the same mindset, European central banks currently maintain their own collective and individual innovation labs and experiments, and the DNB is no exception. Today, similar to market-initiated dynamics, the DNB works closely with financial actors, and it also has an innovation hub together with the Dutch Authority for Financial Markets (AFM), with the purpose of conducting experiments, establishing contacts, and supporting startups and other technological projects as a regulatory and supervisory entity. ${ }^{5}$ The involvement of Dutch regulators in these networks and technological experiments reflects the same relevance of informal and mundane connections as market efforts. My interviewee at the DNB mentioned that aside from keeping up with news through digital social media, there was a network of people from the industry with whom she maintained regular contact regarding emerging experiments and technologies. Regulators do not only have their own experiments, but also participate in the market space ecosystem by becoming involved in private experiments.

Indeed, the involvement of regulators in experiments is something of interest to market players. In the spirit of digital experimentation, and following market needs and demands, the DNB and the AFM have not only created the open innovation lab, but also a regulatory sandbox under the country's regulatory and supervisory twin peaks model. The regulatory sandbox works as an informal, supervised environment where market players can test the grounds for the development of technology. They can also receive advice on existing regulations and close supervision from the legal authorities that crosscut each project's legal demands. It is thus an environment where regulators can keep up with the fast pace of digital innovation and cope, or collaborate, with projects that do not fully fit into existing regulatory frameworks (see also Thiemann and Lepoutre, 2017). This openness and pro-experimentation environment is attractive for incumbent Dutch market players and startups, but also for projects from other countries with more conservative regulatory and supervisory approaches.

In addition to the internal experiments and regulatory sandbox of the European central banks, the DNB and AFM also collaborate with other regulatory authorities such as the Consumer Markets Authority (CMA) and the Dutch Data Protection Authority (DDPA). These 
collaborations are based on the idea that not all innovation deals exclusively with finance or fintech, but rather crosscuts different legal configurations. These concerted efforts aim to create an environment of 'regulatory soundness' based on the idea of openness to innovation.

From the side of the financial regulators and supervisors, the underlying idea behind the sandbox is that they should anticipate and keep up with digital innovations in the early stages, before they achieve systemic significance. Moreover, the aim is to assess whether a given technology could be of use for market supervision and for the creation of more stable financial markets and safe digital transactions and interactions. On the side of market players, the idea is that by consulting with regulators, the different regulatory needs of each project can be made clear, incumbents can structure their manoeuvring as financial intermediaries and experiments can gain legitimisation by being embedded in close market-regulator collaborative networks.

Dutch regulatory and governmental measures are welcomed by incumbent and startup market players, as my interviewee at the NVB suggested when talking about the stricter regulatory contexts in other EU countries compared to the more open environment in the Netherlands. The possibility of provoking regulatory arbitrage within blockchain experiments, by attracting projects and competing - albeit at different levels - with other European countries, was considered by this informant to be part of the competitiveness of the country within a European - but also global - financial and economic context. In addition, through innovation labs and hubs, both financial incumbents and efforts in the regulatory sandbox help startups to assess their activity in legal terms. As mentioned, this includes advice on existing regulations and enhanced awareness when there is a need to create new ones, but also advice on activity modelling, i.e., whether or not to change a business model to avoid long, bureaucratic and expensive legal procedures.

If within Europe there is a certain degree of regulatory arbitrage in crypto businesses between EU and EEA countries with loose financial regulations, for instance - then the Dutch regulatory sandbox aims, among other things, to attract innovative tech businesses. Its appeal stems from its prophylactic features, which not only create space for a degree of activity modelling in the early-stage experiments with digital technologies, but are also quite liberal in regulatory terms.

The Dutch innovation- and business-friendly environment is promoted internationally as a national 'brand' of an EU country that welcomes new businesses and innovative projects, adding to the existing pro-business corporate tax regime. The proactivity of regulatory entities in the country is thus one of the signs of this openness, which in practice translates into the idea that the regulator 'goes outside'. This means that the DNB and AFM participate in innovation-related events, connect with startups, keep networks growing in these arenas, and, under the regulatory sandbox flag, make themselves not only available to advise, debate and accommodate projects within existing regulatory frameworks, but also to propose new regulatory arrangements when needed. These processes of 'going outside' imply, and are sustained by, the maintenance of more casual connections and open relationships between members of the various regulatory institutions, incumbent and startup market actors, and government representatives.

Despite the fact that regulatory sandboxes exist in other EU countries, the close and informal interactional model described above has been longstanding in the Dutch context (Thiemann and Lepoutre, 2017). It is characterised by certain interactional particularities that operate in digital identification and blockchain markets, as well as efforts to promote the Netherlands as an attractive and innovative jurisdiction for businesses. 


\section{The market and the government: Public-private networks in experimentation}

Very soon after my arrival in the Netherlands for my fieldwork, I attended the Dutch Blockchain Hackathon in Groningen between 10 and 12 February as a volunteer. The event was organised by the Dutch Chain, a group of young people promoting experimentation to find use-cases for blockchain. In the various presentations and comment sessions made throughout the event, the organisers repeatedly emphasised that the hackathon was designed to solve practical problems using blockchain. These practical problems were related not only to general blockchain infrastructure development, but also to the particular interests of the event's members, sponsors and partners, which included government agencies and municipalities. Members included the Dutch Ministry of Education and the Ministry of Finance, while a pension fund was the main sponsor. Other participating members were banks, several service providers (IT, energy, and so on), representatives of local government (municipalities, provinces), innovation networks such as the Startup Delta, universities, and Microsoft, IBM and Deloitte taking on major tech and advisory roles. The DNB and AFM were the regulatory representatives at the hackathon. Added to these, there were many invitees, mostly business, legal and tech experts from different companies and sectors, offering advice to the programming teams.

The project competition tracks were chosen according to the sponsors' needs: digital identity (a constant in most of the networks I came across), the future of pensions, energy, and the future of government. Adding to this, most of the teams at the event came from the partners' own innovation labs and training centres, or were employees of stakeholder businesses or organisations. Thus, despite promoting an open and collaborative environment to build a blockchain ecosystem, the hackathon was also a way of strengthening or reproducing existing business and governance circles (Powell, 1990; Linn, 1999; Kogut, 2012).

Among the projects were various teams looking at digital identity management with banking, self-sovereign identification, and solutions for refugee identification and asylum seeking processes. It was possible to see that in the hackathon, several branches of subjectfocused business ecosystems intersected with the blockchain ecosystem. Throughout my fieldwork, it was notable how blockchain technology, the focus of this event, was only one of many branches of multi-tech experimentation practices, and that the possible uses for the technology - regarding its incorporation for the improvement of existing software - cross-cut various priority areas where experiments with various digital technologies were being made.

During the hackathon, I came across iDIN4.0, an experiment exploring the possibility of linking iDIN to a blockchain protocol. I interviewed the founder of the project related to this experiment, also leader of the hackathon team. He was a young developer and entrepreneur who explained in our interview how participating in the blockchain hackathon was relevant to his current startup project, which aimed to execute real estate contracts on a blockchain in regulated contexts. This idea demanded the creation of notary nodes - nodes in a blockchain through which official notaries can oversee smart contract execution and transactions - and the identification of people or entities in a blockchain network. The idea for the pilot that my interviewee's team was working on during the hackathon departed from the proposal that iDIN4.0 could be used to identify pseudonymous blockchain IDs (keys) by linking them to a real person through iDIN. As happens with other projects, particularly in the financial sector, the iDIN4.0 team was taking advantage of existing software and looking to incorporate it into their blockchain project in a way that would comply with identification and privacy regulations (eIDAS, 2014; EU, 2016a). 
The hackathon context revealed some of the actors investing in blockchain technology, as well as the forms in which they connect. It shed light on financial and corporate organisations' incorporation of the technology into current business models and digital infrastructure (Swartz, 2017), and on the ways in which 'interesting' startups are found. This was visible in the case of iDIN4.0, and the use of iDIN as the basis for a blockchain experiment: the team was connected to people at hyperledger, its blockchain provider, and at the NVB and DPA, who were members of the iDIN scheme, all of whom were represented at the hackathon.

Beyond events focused on experimental practice, like the hackathon, other - more formal - groups were forming in the Netherlands at the time of my fieldwork. These were more oriented towards the creation and promotion of a national grassroots Dutch blockchain ecosystem. The Dutch Blockchain Coalition is an example of one such group. The project was launched at an event I attended that took place at the Ministry of Economic Affairs. The idea began with the intention to create a research structure around the blockchain protocol, though it rapidly transformed into a coalition with a more practical approach to the subject, following demands from private actors to create added-value use-cases for blockchain. As a subsection of the Dutch Digital Delta (one of various collaborative platforms aimed at enhancing organisational cross-connectivity in digital innovation arenas in order to better respond to ICT challenges and to capitalise on digital technologies), the DBC follows roughly the same principles. ${ }^{6}$ When I met its founders, who could be described as strategic connectivity facilitators, the coalition was already a dynamic high-level heterogeneous network of organisations and institutions that included more than 24 members, among which were the four major Dutch commercial banks (ING, ABN-AMRO, SNS and Rabobank), various tech universities and research institutions, notaries and auditors, as well as four ministries (economic affairs, infrastructure, justice, and kingdom relations). The particularity of the DBC was its focus on the creation of substantial connections with government, and the establishment of an attractive national profile for the Netherlands within the developing digital innovation landscapes in the EU; in this case, with a specific focus on blockchain technology.

At the time of its launch, the main priority of the group was identity; later, other lines of action were added, such as smart contracts and human capital. One of the founding members of the coalition explained to me how they aimed to promote better connections between private actors, ministries and regulators in order to establish a national experimentation environment. He also talked about the minimal dialogue they had with political representatives and about the uncertainties brought about by unstable political will (my fieldwork period covered the months before, and the month of, the general elections in the Netherlands [March 2017]) regarding experimentation with and the design of digital infrastructure that is deeply embedded with government matters such as digital identification. At the time of my fieldwork, political ambition was seen as a still unstable - yet crucial - dimension to consummate a competitive national experimentation environment for blockchain technology. Beyond being a 'hot topic' for the blockchain ecosystem at the time, the DBC's focus on digital identification a priority of the DSM framework promoted at the EU level - was also an effort to align the coalition objectives with EU directives with which governments and identification providers will eventually have to comply.

Overall, the aim of this group was to answer government, or EU-wide, needs, as well as to further the desire to innovate through blockchain technology - a potentially promising technology for which investments were increasing at the time, but which had yet to achieve widespread confidence to support its adoption (Probst et al., 2016). Being a sort of publicprivate grassroots business group (i.e., a formalised network based on informal contacts and initiatives), and internationally connected, the DBC is not a branch of any EU initiative such as 
the DSM EU Blockchain. ${ }^{7}$ It is, rather, a strategic alliance created for the enhancement of a national ecosystem, which is attractive to international competitive markets through wellinformed, open experimentation cultures focusing on bridging sector, regulatory, jurisdictional and government interests within ongoing networked experimentation cultures in the Netherlands.

\section{Conclusion}

The market-making landscapes analysed above are inhabited by communities engaged in a negotiated collaboration to build a blockchain ecosystem, based on formal and informal relational ties, through which knowledge and experience are created and strengthened (Todeva, 2006). These ties are an important relational feature in the quest for active and meaningful (value-adding) participation in an emerging ecosystem related to blockchain, identification markets and, more broadly, the growth of a platform economy (Langley and Leyshon, 2017). They take the form of socio-technical assemblages composed of manifold situational liaisons. These include informal interactions between stakeholders in everyday life, as seen in the local and global grassroots networking efforts of banks, and other financial actors, but also of the Dutch Central Bank and the Dutch Authority for Financial Markets. They also include the interactions between startups, existing software, financial incumbents (in this case, I focused on banks, but the networks extend to other financial institutions depending on the subject and intention of the experiments), and supervisory and regulatory entities and frameworks, as seen in the iDIN4.0 example from the Dutch blockchain hackathon. Finally, they also encompass the high-level networking efforts made by the actors invested in the Dutch Blockchain Coalition, aimed at enhancing national competitiveness at an international level.

These pragmatic efforts take place in a networking context where old models of business network formation are reproduced, but also expanded through informal ties that reach not only national but also global connections. On the one hand, political, market and regulatory relations, as well as private actor competition, are informally and conversationally maintained (Black, 2002) - and expanded - by technology and as part of the quest to establish a convenient experimentation ecosystem. On the other hand, if market actors collaborate to compete in a convenient environment, so do jurisdictions. This means that market players collaborate to create product standards or a common infrastructure, in articulation with legal authorities, that may work as a legitimate marked-out activity field. But, together with governments and regulatory bodies, they are also part of collaborative efforts to promote an internationally competitive jurisdiction for attracting businesses.

In the Netherlands, where a certain over-embeddedness of regulators in markets has been observed (Thiemann and Lepoutre, 2017), the active participation of regulatory bodies in tech experimentation phases occupies a somewhat liminal position. On the one hand, there is early control of market participants' activities through a process of informal supervision in the beginning stages of tech development, i.e., a regulatory sandbox that seems to work as a preventive measure for regulatory arbitrage out of the country, and as a means to attract business (Thiemann and Lepoutre, 2017: 1776; Riles, 2014). On the other hand, in this environment, market players are able to (re)define and legitimise projects according to regulatory boundaries - a sort of creative modelling. While financial incumbents did already have this ability - through participation in numerous public consultations and periodic meetings - my emphasis is on the informality that characterises the current environment, on the opening of this phenomenon to smaller actors (startups and entrepreneurs) as well as to 
financial incumbents and government and regulatory institutions, but also on the open-ended and flexible character of these relations. This translates into market players' pursuit of regulatory and government involvement in experiments - which seems to be a quest for early experiment legitimisation and market establishment - and regulators' caution regarding technological innovation while embedding themselves within emerging markets.

These connections reflect processes of networking and bricolage in digital innovation and technological experiments (Engelen et al., 2010), and the prevalent and important role of government and regulatory measures in making markets (Miller and Morris, 1999; Todeva, 2006). In these processes and conversations (Black, 2002), regulatory entities seem to have one hand in keeping markets safe, and the other in market participation, all under the wide collaborative hat of attracting business to their country - something which, in the case of the Netherlands, is not new (Thiemann and Lepoutre, 2017). In these informal relations, which seem to be the grassroots component of formal initiatives, as seen in the examples above, there are constant negotiations between the maintenance of a sustainable financial system, the satisfaction of market demands, and the competition among jurisdictions for business attractiveness.

While it is in the regulatory field that the presented findings reveal more direct processes of action within, and particularities of, the Dutch context, their implications also transcend these dimensions. The networked configurations that I have tried to disentangle in this article, which, through mundane connections, have wide reflections on national and international markets and governance, are key to analysing the different contexts, intentions and relations that compose global financial and tech landscapes and that keep them in motion. They do so by tackling wider aspects related to the development of fintech, and the entrance of new startup actors and a new ethos in increasingly informalised governance structures enabled by technology and modes of operation that transcend finance and markets (Mayer, 2012).

Financial market-making models and business network formation are expanding beyond markets to encompass areas that, through digital technologies, will become ubiquitous in people's lives - such as digital ID - and will transcend the boundaries between public and private digital infrastructure - government and governance technologies - and thus strengthen the connections between, and embeddedness within, the market and politics. In the context of platform capitalism, these connections and their transformation seem like a crucial feature and bring about the need for new means of understanding market-making processes and the role of new digital architectures in them (Caliskan, 2020). These implicate rent-seeking business models expanded at a global scale (Langley and Leyshon, 2017), which, although going beyond particular geographies of action, need to be looked at globally but also locally and in depth. They also imply that, in certain areas such as digital identification, governments, regulators, and financial and technological organisations are all becoming equal market players under increasingly liberalised tech experimentation contexts that, due to their experimental character, foster new informalised practices. These latter practices make the boundaries between the market, the regulator and the state increasingly 'mobile' and fuzzy. I believe that these practices should be further researched, and that they will demand for new modes of regulatory accountability (Morgan and Yeung, 2007) and new forms of tackling such fluid relations, which increasingly pertain to hybrid - actual and digital - socio-technical collectives that are often hard to understand. 


\section{Acknowledgements}

This work was supported by FCT, I.P., the Portuguese national funding agency for science, research, and technology, under the Project UIDB/04521/2020. I thank the reviewers of previous versions of the manuscript for their valuable comments and suggestions. I also thank Daniel Seabra Lopes and Sandra Faustino for comments and suggestions throughout the writing process.

\section{Notes}

1. For more on legal heterogeneity in the EU/EEA regarding cryptocurrencies and blockchain, see Dewey (2019).

2. iDEAL is a digital payments scheme owned by banks and the Dutch Payments Association.

3. At the time of research, and despite further developments, the iDIN authentication mechanism could only be used for some government-related matters. For more in-depth analysis of Dutch digital identification software, see Zwilling (2017).

4. Blockchain technology uses double key encryption (Nakamoto, 2008).

5. The DNB issued a statement about the lack of maturity of blockchain technology, at least in finance and monetary terms, which currently prevents it from going mainstream (DNB, 2018).

6. This also includes Startup Delta, a startup business incubator involved in blockchain events, labs, and experimentation ecosystems.

7. More information on this is available at: <https://ec.europa.eu/digital-single-market/en/ blockchain-technologies>.

\section{References}

Accenture (2013) The Future of Identity in Banking. Available at: <https://www.accenture.com/ _acnmedia/Accenture/Conversion-Assets/DotCom/Documents/Global/PDF/Dualpub_9/ Accenture-Future-Identity-Banking.pdf>. Accessed 26 October 2018.

Arner, D., Barberis, J. and Buckley, R. (2017) Fintech, regtech and the reconceptualization of financial regulation. Northwestern Journal of International Law and Business, 37(3): 371-413.

Black, J. (2002). Regulatory conversations. Journal of Law and Society, 29(1): 163-96.

Caliskan, K. (2020) Data money: The socio-technical infrastructure of cryptocurrency blockchains. Economy and Society, 49(4): 540-61.

Callon, M. (1990) Techno-economic networks and irreversibility. Sociological Review, 38(51): 132-61.

Carruthers, B. and Stinchcombe, A. (1999) The social structure of liquidity: Flexibility, markets and states. Theory and Society, 28(3): 353-82.

Davidson, S., Di Filippi, P. and Potts, J. (2016) Economics of blockchain. Proceedings of public choice conference, 2016. Fort Lauderdale, United States. Available at: < https://hal.archives-ouvertes.fr/ hal-01382002>. Accessed 10 October 2019.

Dewey, J. (ed.) (2019) Global Legal Insights: Blockchain and Cryptocurrency. UK: Global Legal Group.

DNB [Dutch Central Bank] (2018) Dutch Central Bank (DNB) Bulletin: DNB experiments with blockchain technology. Available at: <https://www.dnb.nl/en/news/news-and-archive/DNBulletin2018/ dnb376502.jsp\#>. Accessed 17 July 2020.

DuPont, Q. and Maurer, B. (2015) Ledgers and law in the blockchain. King's Review Magazine. Available at: <http://kingsreview.co.uk/articles/ledgers-and-law-in-the-blockchain/>.

Eckert, S. and Bõrzel, T.A. (2012) Experimentalist governance: An introduction. Regulation and Governance, 6(3): 371-77. 
Faria, I. (2019) Trust, reputation and ambiguous freedoms: Financial institutions and subversive libertarians navigating blockchain, markets, and regulation. Journal of Cultural Economy, 12(2): 119-32.

Faustino, S. (2019) How metaphors matter: An ethnography of blockchain-based re-descriptions of the world. Journal of Cultural Economy, 12(6): 478-90.

EBF [European Banking Federation] (2016) Innovate, Collaborate, Deploy. European Banking Federation Vision for Banking in the Digital Single Market. Available at: <https://www.ebf.eu/wpcontent/uploads/2017/05/EBF-vision-for-banking-in-the-Digital-Single-Market-October-2016.pdf>. Accessed 10 October 2019.

ECB [European Central Bank] (2018) Virtual or virtueless? The evolution of money in the digital age. Lecture by Yves Mersch, member of the executive board of the ECB, Official Monetary and Financial Institutions Forum, London, 8 February. Available at: <https://www.ecb.europa.eu/press/ key/date/2018/html/ecb.sp180208.en.html>. Accessed 17 July 2019.

eIDAS (2014) Regulation (EU) No 910/2014 of the European Parliament and European Commission, of the 23 July 2014. On electronic identification and trust services for electronic transactions in the internal market and repealing Directive 1999/93/EC. Available at: <https://ec.europa.eu/ futurium/en/system/files/ged/eidas_regulation.pdf>. Accessed 11 January 2020.

Engelen, E., Ertürk, I., Froud, J., Leaver, A. and Williams, K. (2010) Reconceptualizing financial innovation: Frame, conjuncture and bricolage. Economy and Society, 39(1): 33-63.

Engelen, E. (2015) Don't mind the 'funding gap': What Dutch post crisis storytelling tells us about elite politics in financialized capitalism. Environment and Planning A, 47(8): 1606-23.

Ertürk, I. and Solari, S. (2007) Banks as continuous reinvention. New Political Economy, 12(3): 369-88. Ertürk, I. (2015) Financialization, bank business models and the limit of post-crisis bank regulation. Journal of Banking Regulation, 17(1-2): 60-72.

EU [European Union] (2015) A digital single market strategy for Europe - COM (2015) 192 final. Available at: <https://ec.europa.eu/digital-single-market/en/news/digital-single-market-strategyeurope-com2015-192-final>. Accessed 11 January 2019.

EU [European Union] (2016a) Regulation (EU) 2016/679 of the European Parliament and European Commission, of 27 April 2016. On the protection of natural persons with regard to the processing of personal data and on the free movement of such data, and repealing, Directive 95/46/EC (General Data Protection Regulation/GDPR). Available at: <http://eur-lex.europa.eu/legal-content/ EN/TXT/PDF/?uri=CELEX:32016R0679andfrom=EN>. Accessed 11 September 2020.

Fernandez, R. and Wigger, A. (2016) Lehman Brothers in the Dutch offshore financial centre: The role of shadow banking in increasing leverage and facilitating debt. Economy and Society, 45(3-4): 407-30.

Kochenov, D. and Gstrein, O. (2019). Digital identity and distributed ledger technology: Paving the way to a neo-feudal brave new world? University of Groningen, Faculty of Law Research Paper 31/2019. Available at: <https://ssrn.com/abstract=3433498>. Accessed 23 April 2020.

Kogut, B., Walker, G. and Dong-Jae, K. (1995) Cooperation and entry induction as an extension of business rivalry. Research Policy, 24(1): 77-95.

Kogut, B. (2012) Business groups and financial markets as emergent phenomena. In: Knorr-Cetina, K. and Preda, A. (eds.) The Oxford Handbook of the Sociology of Finance. Oxford: Oxford University Press, 126-45.

Langley, P. and Leyshon, A. (2017) Platform capitalism: The intermediation and capitalisation of digital economic circulation. Finance and Society, 3(1): 11-31.

Latour, B. (2005) Reassembling the Social. Oxford: Oxford University Press.

Lopes, D. (2018) Under pressure: Financial supervision in the post-2008 European Union. In: Carrier, J. (ed.) Economy, Crime and Wrong in a Neoliberal Era. Oxford: Berghahn Books, 93-115. 
Marcus, G. (1995) Ethnography in/of the world system: The emergence of multi-sited ethnography. Annual Review of Anthropology, 24: 95-117.

Maurer, B., Nelms, T. and Swartz, L. (2013) 'When perhaps the real problem is money itself!': The practical materiality of Bitcoin. Social Semiotics, 23(2): 261-77.

Mayer, S. (2011) Embedded politics, growing informalization? How NATO and the EU transform provision of external security. Contemporary Security Policy, 32(2): 308-33.

Miller, W. and Morris, L. (1999). Fourth Generation R\&D: Managing Knowledge, Technology and Innovation. New York: Wiley.

Moore, J. (1993) Predators and prey: A new ecology of competition. Harvard Business Review, 71(3): 75-86.

Morgan, B. and Yeung, K. (2007) An Introduction to Law and Regulation. Cambridge: Cambridge University Press.

Nakamoto, S. (2008) Bitcoin: A peer-to-peer electronic cash system. Available at: $<w w w . c r y p t o v e s t . c o . u k>$. Accessed 17 October 2019.

NVB [Dutch Banking Association] and PwC [Pricewaterhouse Coopers] (2017) How Bankers Can Become Innovation Leaders Again. Available at: <https://www.nvb.nl/.../001608_pwc-howbankers-can-become-innovation-leaders-again-2017.pdf>. Accessed 26 October 2019.

O'Dwyer, R. (2015). Money talks: The enclosure of mobile payments. In: Lovink, G., Tkacz, N. and de Vries, P. (eds.) MoneyLab Reader: An Intervention in Digital Economy. Amsterdam: Institute of Network Cultures, 230-44.

Powell, W. (1990) Neither market, nor hierarchy: Network forms of organization. Research on Organizational Behaviour, 12: 295-336.

Probst, L., Frideres, L., Cambier, B., Martinez-Diaz, C. and PwC Luxembourg. (2016) Report on blockchain: Blockchain applications and services. Business innovation observatory. contract $\mathrm{n}^{\circ}$ 190/PP/ENT/CIP/12/C/N03C01. Available at: <https://ec.europa.eu/.../innovation/businessinnovation-observatory/trend-reports_en>. Accessed 10 October 2019.

PwC [Pricewaterhouse Coopers] (2016) Know your customer quick reference guide. Available at: $<$ https://www.pwc.com/gx/en/financial-services/publications/assets/pwc-anti-money-laundering2016. pdf>. Accessed 26 October 2019.

Riles, A. (2014) Managing regulatory arbitrage: A conflict of laws approach. Cornell International Law Journal, 47(1): 47-119.

Stone, R.W. (2011) Controlling Institutions: International Organizations and the Global Economy. Cambridge: Cambridge University Press.

Swartz, L. (2017) Blockchain dreams: Imagining techno-economic alternatives after Bitcoin. In: Castells, M. et al. (eds.) Another Economy is Possible: Culture and Economy in a Time of Crisis. Cambridge: Polity, 82-105.

Swartz, L. (2018) What was Bitcoin, what will it be? The techno-economic imaginaries of a new money technology. Cultural Studies, 32(4): 623-50.

Thiemann, M. and Lepoutre, J. (2017) Stitched on the edge: Rule evasion, embedded regulators and the evolution of markets. American Journal of Sociology, 122(6): 1775-1821.

Todeva, E. (2006) Business Networks: Strategy and Structure. London: Routledge.

Tsang, C. (2019) From industry sandbox to supervisory control box: Rethinking the role of the regulators in the era of fintech. University of Illinois Journal of Law, Technology and Policy, 355-404.

Walker, G., Kogut, B. and Shan, W. (1997) Social capital, structural holes and the formation of an industry network. Organization Science, 8(2): 109-25.

Weiss, M. (2020). Varieties of privatization: Informal networks, trust and state control of the commanding heights. Journal of International Political Economy, https://doi.org/ 10.1080/09692290.2020.1726791 
Zetzsche, D., Buckley, R., Barberis, J. and Arner, D. (2017) Regulating a revolution: From regulatory sandboxes to smart regulation. Fordham Journal of Corporate and Financial Law, 23(1): 34-103.

Zwilling, A. (2017) Electronic Digital Identity Management Systems in the European Union. MA thesis in Information Sciences, Radboud University. Available at: <https://www.ru.nl/publish/pages/ 769526/z_armin_zwilling.pdf>. Accessed 15 August 2019. 